\title{
Evaluation of saps-3 index in patients whith structural brain lesion admitted in intensive care unit (ICU)
}

\author{
C Lopez-Caler ${ }^{1 *}$, MD Arias-Verdú ${ }^{1}$, R Gónzalez-Ortiz ${ }^{1}$ J Moreno-Quintana', E Castillo-Lorente ${ }^{2}$, E Aguilar-Alonso ${ }^{3}$, \\ J Barrueco-Fanconi ${ }^{1}$, G Jiménez-Pérez ${ }^{4}$
}

From ESICM LIVES 2015

Berlin, Germany. 3-7 October 2015

\section{Objectives}

To evaluate SAPS 3 performance in patients with structural brain pathology (traumatic brain injury (TBI) and acute cerebrobrovascular accident) admitted in ICU.

\section{Methods}

We studied all patients admitted with structural brain pathology (traumatic brain injury and acute cerebrobrovascular accident) in three Spanish Hospitals (Hospital Carlos Haya de Malaga, Hospital de Cabra and Neurotraumatológico de Jaén) during four months in 2012 and 2013. We collected clinical and demographics data, mortality and the necessary data to calculate the SAPS-3 indexThe differences between observed-to-predicted mortality were analyzed with the Hosmer-Lemeshow test. SAPS 3 discrimination with regard to hospital mortality, tested using the area under the ROC curve.

$\mathrm{P}<0.05$ was statistically significant (s.s).

\section{Results}

$\mathrm{N}=128$ patients. Traumatic brain injury: 53 patients. Stroke: 75 patients. Mean age was $56.23 \pm 18.56$ years. Gravity according to SAPS-3 was $51.69 \pm 18.56$ points. Mortality predicted by the SAPS- 3 was $25.57 \%$ by the general equation and $26.12 \%$ by geographical area equation. Hospital mortality was $31.2 \%$.We divided the population according to predicted mortality by the general equation of SAPS-3 in: 1) less than 20\%, 2) between $20-40 \%, 3) 40$ $60 \%$, 4) $60-80 \%$, and 5) greater than $80 \%$. The predicted mortality was respectively: $8.2 \%, 28.3 \% 49.2 \%, 68.4 \%$ and $84.8 \%$ and the observed was $6.2 \%, 30 \%, 75 \%, 91 \%$ and
$100 \% ; \mathrm{H}=8.84, \mathrm{GL}=3$, being the differences between predicted and observed statistically significant $(\mathrm{p}<0.05)$. By the geographical area equation we found similar disagreements; $\mathrm{H}=10.61$ ( $\mathrm{p}<0.05$ ) SAPS 3 discrimination with regard to hospital mortality, tested using the area under ROC curve was high: 0.90 (0845-0961).

\section{Conclusions}

Patients with structural brain lesion admitted in ICU (TBI and stroke) have a high value of severity assessed by SAPS-3. The SAPS-3 presents good discrimination in these patients but slightly underestimates mortality, being no very important differences between predicted and observed mortality, but statistically significant.

\section{Authors' details}

'Hospital Regional Universitario Carlos Haya, Intensive Care Unit, Málaga, Spain. ${ }^{2}$ Hospital Neurotraumatologico, Intensive Care Unit, Jaen, Spain. ${ }^{3}$ Hospital Infanta Margarita Cabra, Córfdoba, Spain. ${ }^{4}$ Hospital Regional Universitario Carlos Haya, Intensivo Care Unit, Málaga, Spain.

Published: 1 October 2015

\section{doi:10.1186/2197-425X-3-S1-A833}

Cite this article as: Lopez-Caler et al:: Evaluation of saps-3 index in patients whith structural brain lesion admitted in intensive care unit (ICU). Intensive Care Medicine Experimental 2015 3(Suppl 1):A833. 